\title{
Televised obesity-prevention advertising across US media markets: exposure and content, 2010-2011
}

\author{
Rachel Kornfield ${ }^{1, *}$, Glen Szczypka ${ }^{1}$, Lisa M Powell ${ }^{2}$ and Sherry L Emery ${ }^{1}$ \\ ${ }^{1}$ Health Media Collaboratory, Institute for Health Research and Policy, University of Illinois, 1747 West Roosevelt \\ Road, M/C 275, Chicago, IL 60608, USA: ${ }^{2}$ Health Policy and Administration, School of Public Health, University of \\ Illinois, Chicago, IL, USA
}

Submitted 23 September 2013: Final revision received 13 May 2014: Accepted 22 May 2014: First published online 30 July 2014

\begin{abstract}
Objective: To examine levels of exposure and content characteristics for recent televised obesity-prevention campaigns sponsored by state and community health departments, federal agencies, non-profit organizations and television stations in the USA.

Design: Nielsen television ratings for obesity-prevention advertising were collected for the top seventy-five US media markets and were used to calculate household exposure levels for 2010 and 2011. Governmental advertisements were coded for content.

Setting: United States.

Results: Average household exposure to obesity-prevention campaigns was 2.6 advertisements per month. Exposure increased by $31 \%$ between 2010 and 2011, largely driven by increases in federal advertisements. In 2011, the federal government accounted for $62 \%$ of obesity-prevention exposure, non-profit organizations for $9 \%$, community departments for $8 \%$, state departments for $3 \%$, and television stationsponsored public-service announcements for $17 \%$. The greatest percentage increase between 2010 and 2011 was in community advertising, reflecting efforts funded by the Communities Putting Prevention to Work (CPPW) programme. Among thirty-four state and community campaigns, the majority advocated both healthy eating and physical activity (53\%). Campaigns typically had positive or neutral emotional valence (94\%). Obesity or overweight was mentioned in $47 \%$ of campaigns, but only 9\% specifically advocated weight loss.

Conclusions: Exposure to televised obesity-prevention advertising increased from 2010 to 2011 and was higher than previously found in 1999-2003, apart from in 2003 during the federal VERB campaign. Nevertheless, exposure remains low relative to advertising for unhealthy foods. New federal campaigns have increased exposure to obesity-prevention advertising nationally, while CPPW grants have increased exposure for targeted areas.
\end{abstract}

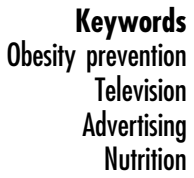

In 2009-2010, the prevalence of obesity in the USA was $18.0 \%$ among children aged 6-11 years, $18.4 \%$ among adolescents aged $12-19$ years ${ }^{(1)}$ and $35.7 \%$ among adults $^{(2)}$. Obesity represents a major public health concern given its association with serious health outcomes including CVD, diabetes mellitus and some cancers ${ }^{(3)}$, as well as social stigma ${ }^{(4)}$ and increased medical costs ${ }^{(5)}$. Interventions have typically addressed two primary causes of obesity: insufficient physical activity and overconsumption of energy-dense foods ${ }^{(6,7)}$. Interventions may be conducted in the community ${ }^{(8,9)}$, in primary health care $^{(10)}$, through policy change ${ }^{(11-13)}$, or through massmedia campaigns including television ${ }^{(14)}$.

Television represents an important component of an obesity-prevention strategy. In a competitive media environment, televised health-promotion campaigns must find effective ways to convey information and inspire behaviour change ${ }^{(15,16)}$. While the long-term impact of obesity-prevention television campaigns on body-weight outcomes remains unclear ${ }^{(17)}$, there is evidence that some recent campaigns with televised components have successfully influenced attitudes related to risk-reducing behaviours such as physical activity and healthy food choices ${ }^{(18-22)}$. The effectiveness of such campaigns depends largely on the level of exposure achieved ${ }^{(23)}$, as well as on the persuasiveness of the messaging. For example, obesity-prevention campaigns may be more effective when they provide concrete behavioural recommendations and when they advocate both dietary change and physical activity ${ }^{(24)}$. The use of certain negative emotional messages and graphic images 
in public health campaigns remains controversial ${ }^{(25)}$, but has been shown to improve message salience and to increase message effectiveness in some contexts ${ }^{(26,27)}$. Both sufficient exposure and persuasive messaging are crucial, especially given the relative resources and expertise of the food industry in marketing unhealthy products such as those high in saturated fat, sugar and sodium, and with television serving as the dominant platform for such advertising ${ }^{(28-31)}$. It is crucial for the public health community to find successful ways to provide counterinformation that might inspire viewers to adopt healthier lifestyles.

Historically, obesity-prevention campaigns have achieved significantly lower exposure than other televised healthpromotion messages. In our prior study of public health television advertising from 1999 to 2003, we identified obesity-prevention campaigns sponsored by state or community health departments in only eight states, and overall exposure levels were far outweighed by tobaccoprevention advertising ${ }^{(32)}$. The launch of the Centers for Disease Control and Prevention's VERB campaign in 2002 represented the first large-scale national obesityprevention television campaign, reaching thirty-nine annual advertisement exposures per household for the top seventy-five US media markets by $2003^{(32)}$. The VERB campaign aired through 2006.

In recent years, a number of additional obesityprevention television campaigns have been launched by state and community health departments, the federal government and non-profit organizations. Beginning in 2010, the US Department of Health and Human Services (DHHS) awarded grants to thirty communities in twentytwo states and the District of Columbia to allocate towards obesity-prevention efforts through the Communities Putting Prevention to Work (CPPW) programme, funded by the American Recovery and Reinvestment Act. In total, \$US 230 million was allocated to obesity-prevention efforts. A number of these efforts included mass-media campaigns that began airing in 2010 or $2011^{(33,34)}$. At the federal level, First Lady Michelle Obama led the Let's Move campaign, the television component of which launched in $2010^{(35)}$. Additional campaigns reflected alliances between federal and state departments as well as private sector or non-profit partners ${ }^{(36)}$.

There is some evidence that the focus and tone of obesity-prevention messages may be shifting among new campaigns $^{(37)}$. For instance, there have been recent calls for obesity-prevention efforts to address the ubiquity of energy-dense foods that are heavily marketed ${ }^{(38-41)}$. Some such efforts have focused on reducing sugar-sweetened beverage (SSB) consumption ${ }^{(22)}$, with one advertisement from the New York City Department of Health's Pouring on the Pounds campaign illustrating the connection between SSB and weight gain with graphic images of fat poured out of soda bottles ${ }^{(42)}$. Some recent campaigns have also raised controversy for their emphasis on body image as a motivator for behaviour change $\mathrm{e}^{(37,43,44)}$. However, messages that emphasize body shape are not necessarily more effective than other message types and could introduce stigma towards obese individuals ${ }^{(45-47)}$. While recent graphic and body weight-focused campaigns have generated publicity, the messaging styles used in recent obesity-prevention campaigns have not been systematically studied. In order to guide efforts to test the effectiveness of obesity-prevention advertising, research should establish the key differences between commonly used public health messages.

In the present study, we analysed the volume and content of public health obesity-prevention advertising campaigns that aired in 2010 and 2011 and reviewed the literature on public health messaging in order to consider these campaigns' potential effectiveness. As in our prior study that assessed data from 1999 to 2003, we quantified exposure for all obesity-prevention campaigns sponsored by federal, state and local governments ${ }^{(32)}$. In the current study, we also expanded our data set to include campaigns sponsored by non-profit organizations and television stations, calculating exposure levels in each of the top seventy-five US media markets for households as well as for specific audience subgroups including adults, children and teens. Since the approaches used in governmentsponsored campaigns are likely to be of particular interest to the public health community, we coded all governmental campaigns for their target audience and main message (i.e. healthy eating, physical activity or both), as in our prior study. For all state and local governmental campaigns, we also characterized additional aspects of the informational content and messaging approach, including the presence of references to weight loss and the emotional valence of advertisements. By providing an overview of exposure levels and message types among recent obesity-prevention campaigns, the present study may inform efforts by the public health community to amplify and improve obesityprevention mass-media campaigns.

\section{Methods}

Through Kantar Media, a market research company that monitors advertising across a number of media channels including television, we reviewed a comprehensive database of television advertisements that aired in 2010 and 2011 to identify campaigns sponsored by federal, state and local governments, non-profit organizations and other unpaid public-service announcements (PSA) sponsored by television stations. Among these, we identified all advertisements that advocated healthy eating or exercise, drew attention to obesity or encouraged weight loss. We excluded any advertisements that advocated healthy eating or physical activity in support of some other concrete health goal that did not overlap with obesity prevention, such as those that encouraged healthy diet in order to prevent prostate cancer or to improve performance in school. As previously 
described $^{(32)}$, identification of relevant advertisements was typically straightforward based on searches for obesity- and health-related keywords in organization and campaign names. For organizations where we captured any relevant advertisements with our keyword searches, and for all public health departments, we also manually reviewed Kantar's descriptions of all campaigns to ensure data capture was complete. For example, the Let's Move campaign was captured by review of all campaigns sponsored by the US DHHS and also by keyword searches for 'health' and 'move'. Where campaign names were ambiguous, we reviewed descriptions of individual advertisements. Typical descriptors of advertisements offered a few words, such as 'Prevent Childhood Obesity'. When there was ambiguity in this descriptor, the digital copy of the advertisement was reviewed, allowing for inclusion or elimination.

For advertisements identified for inclusion based on our relevance criteria, Nielsen Media Research provided data on gross rating points (GRP), representing the fraction of television households (used to approximate the general audience) reached by each advertisement's occurrence multiplied by the number of occurrences. We also obtained targeted rating points for viewers aged 2-11, $12-17$ or 18 + years. Ratings were captured for network, syndicated and spot television. Ratings were also available for national cable, although they were not available for spot cable campaigns, the minority of cable advertising that airs only in local markets. All ratings were calculated at the level of the designated market area (DMA), a contiguous set of counties comprising a metropolitan area in which the population receives the same (or similar) television offerings. We divided GRP values by 100 to derive the average number of times each campaign was broadcast to a television household ('exposures'). We examined campaigns that aired in the top seventy-five US DMA, representing approximately $78 \%$ of the US population and encompassing all major metropolitan areas ${ }^{(48)}$.

As in our prior study, video copies of governmentsponsored obesity-prevention advertisements were coded by named sponsoring organization, including any private partners listed. We also coded campaign message (physical activity, healthy eating or both) and the target age of the audience, which was typically apparent based on the age of the main character(s) depicted. If the age of the main character(s) was not obvious and the audience was not clearly specified in the narration, the coding rules instructed to code the advertisement as 'general audience'.

We selected all state and community campaigns for additional in-depth coding, since these represented a manageable set of videos encompassing a variety of executions. We coded eighty-six unique videos representing thirty-four campaigns, with between one and six representative videos coded per campaign. A number of codes addressed the persuasive potential of advertisements, including their elicitation of an emotional response, a feature associated with campaign effectiveness in some public health contexts ${ }^{(27)}$.
Specifically, advertisements were coded for their overall emotional valence, defined by whether or not the advertisement includes images or narration evoking emotion that is positive (i.e. hope, humour, laughter), negative (i.e. fear, sadness, horror) or neutral. Since graphic imagery is frequently used in fear appeals ${ }^{(49)}$, we also coded instances where advertisements contained strikingly vivid, realistic images that illustrated the harmful and life-threatening effects of unhealthy behaviours. Given that some recent health marketing campaigns have drawn publicity for their use of humour ${ }^{(50)}$, we also coded advertisements that had elements perceived as intended to inspire laughter. We further coded for whether advertisements presented negative health consequences of an unhealthy lifestyle, noting mentions of specific disease risks such as diabetes and heart disease; such depictions may or may not employ graphic images or evoke negative emotion ${ }^{(27)}$. Since use of statistics in depicting health effects may have implications for message effectiveness ${ }^{(51)}$, we coded advertisements for inclusion of any statistics about obesity-related diseases, such as prevalence rates or risk levels among obese individuals. We also adapted codes related to adoption type ${ }^{(15)}$, focusing on whether advertisements promoted adoption/increase of healthy behaviours (such as daily physical activity), cessation/reduction of unhealthy behaviours (such as screen time or unhealthy food consumption), or did both.

We further coded advertisements for additional elements that have recently been emphasized or debated in the public health community's framing of the obesity epidemic. Given recent calls for obesity-prevention efforts to address sedentary screen time and the ubiquity of heavily marketed unhealthy foods, we coded for any explicit references to screen time and also for any images or mentions of unhealthy food products: 'fast food' products sold in restaurants or stores with preheated or precooked ingredients and served to the customer in a packaged form for take-out (e.g. burgers and fries); 'junk food' such as bags of chips, cookies, doughnuts or candy; and SSB including sodas, sports drinks, sweetened tea, sweetened fruit drinks and punches. Some messages exclusively advocated behaviours related to SSB consumption and were coded as such. Since emphasis on body weight has recently drawn controversy in obesity-prevention campaigns, we also coded messages for any reference to overweight or obesity and for whether advertisements mentioned weight loss as one of the explicit goals of lifestyle change. We noted whether advertisements focused exclusively on obesity-prevention or whether they also advocated additional behaviour changes such as vaccination or smoking cessation. Finally, we coded advertisements for whether or not they linked to specific information sources or services, such as websites, call lines, health-care providers or social media.

Coding was performed by two experienced coders who referenced a codebook. We considered and piloted some additional message features, such as whether advertisements presented and addressed counter-arguments for 
behaviour change ${ }^{(51)}$, but eventually dropped codes where we could not achieve good levels of inter-rater reliability. In other cases, codes were aggregated to improve reliability. For example, positive and neutral emotional valence were initially coded separately but later aggregated since they proved difficult for coders to distinguish. In a double-coded sample of thirty-five videos, $\kappa$ for our final codes ranged from 0.62 to 1.00 , with an average of 0.77 across twenty variables. Since $\kappa$ is an especially conservative estimate of inter-rater reliability when code frequency is unbalanced ${ }^{(52)}$, we retained codes with relatively low $\kappa$ (under $0 \cdot 7$ ) in certain cases where they had low occurrence in the data (use of humour and mentions of screen time). In these cases, $\kappa$ may also have suffered from the subjectivity involved in identifying humour and from the variety of language through which references to 'screen time' can be conveyed. Coding discrepancies in the overlap sample were adjudicated by consensus. Content elements of individual advertisements were aggregated to the campaign level in presenting our results.

\section{Results}

Household exposure to televised obesity-prevention advertising increased from $2 \cdot 3$ to 3.0 advertisements per month between 2010 and 2011, a 31\% increase that was driven largely by exposure to federal advertisements (Table 1). Non-profit and state-sponsored advertisements declined (by $60 \%$ and $72 \%$, respectively), whereas community advertisements were minimal in 2010, but increased by $545 \%$ in 2011, exceeding state advertising. This increase largely reflected CPPW-funded efforts; for the year 2011, eleven CPPW-funded campaigns accounted for approximately $87 \%$ of community exposure (see Appendix). In 2011, federal campaigns accounted for $62 \%$ of exposure, television station-sponsored PSA for $17 \%$, non-profit organizations for $9 \%$, community health departments for $8 \%$, and state health departments for $3 \%$. The non-profit organizations with highest exposure during the study were America on the Move Foundation, the American Diabetes Association and the American Heart Association. The television station-sponsored PSA with the highest exposure was the More You Know campaign on NBC.
Table 2 describes variation in exposure by viewer age and DMA for 2010 and 2011. Adults (18+ years) were exposed to more monthly obesity-prevention advertisements (1.4) than children (1.2) or teens (0.9). Children were the most exposed group for federal campaigns (0.7 advertisements per month). There was wide variation in household exposure by DMA, with an SD of 1.3 monthly advertisements and a sevenfold difference between the most exposed market (Columbus, $\mathrm{OH}$ ) and the least (Omaha, NE). Variation was highest for community advertising and lowest for federal advertising. Although exposure to state and community campaigns was low when averaged across all seventy-five DMA, mean exposure was considerably higher when considering only the DMA with non-zero exposure levels, with 0.6 state advertisements per month across thirty DMA and 0.5 community advertisements per month across twenty DMA. State and community campaigns represented at least a third of obesity-prevention exposure in a number of markets, reflecting a combination of efforts through CPPW, Champions for Change (in California and Arizona) and other programmes. These markets were: Tucson, AZ; Los Angeles, CA; Fresno, CA; San Antonio, TX; Phoenix, AZ; Sacramento, CA; and Flint, MI.

Table 3 shows exposure, main message and targeting of federal campaigns. Increasing federal exposure from 2010 to 2011 corresponds largely to the late 2010 launch of the Let's Move campaign, which accounted for $69 \%$ of federal exposure by 2011. A number of additional federal campaigns were associated with modest ratings and were typically targeted towards youth. Physical activity was advocated in $83 \%$ of federal campaigns and dietary change in $67 \%$, with $50 \%$ advocating both.

Of a total of thirty-four state and community campaigns that we content-coded (Table 4), nineteen were community efforts, fourteen were state efforts and one was sponsored by the Cherokee Nation in Oklahoma. Only three (9\%) targeted youth while the rest targeted general audiences $(47 \%)$ or parents (44\%). Healthy eating was advocated in $85 \%$ of campaigns and physical activity in $65 \%$, with $53 \%$ advocating both. Fifty-six per cent of campaigns included specific nutritional recommendations, such as counting calories, reducing SSB, drinking low-fat milk, or eating fruits, vegetables or whole grains. Three campaigns ( $9 \%$ ) focused primarily on SSB consumption. The

Table 1 Monthly obesity-prevention advertisements viewed by US households, 2010-2011

\begin{tabular}{lccr}
\hline Sponsoring organization & Advertisements per month, 2010 & Advertisements per month, 2011 & Change (\%) \\
\hline Federal & 0.8 & 1.8 & 128 \\
Non-profit organization & 0.7 & 0.3 & -60 \\
Television station & 0.4 & 0.5 & 40 \\
State & 0.3 & 0.1 & -72 \\
Community & 0.0 & 0.2 & 545 \\
Total $^{*}$ & 2.3 & 3.0 & 31 \\
\hline
\end{tabular}

${ }^{*}$ Exposure levels by sponsoring organization may not sum to total row numbers due to rounding. 
Table 2 Monthly obesity-prevention advertisements viewed by US households, by age and designated market area (DMA), 2010-2011

\begin{tabular}{|c|c|c|c|c|c|c|c|c|c|}
\hline \multirow[b]{2}{*}{ Sponsoring organization } & \multicolumn{4}{|c|}{ Average exposure for top 75 DMA } & \multicolumn{5}{|c|}{ Variation in household exposure by DMA* } \\
\hline & Age $2-11$ years & Age $12-17$ years & Age $18+$ years & Households & SD & sD/mean (\%) & Minimum & Maximum & Markets \\
\hline Federal & 0.7 & 0.5 & 0.6 & $1 \cdot 3$ & 0.4 & 31 & 0.8 (Charlotte, NC) & 2.5 (Tulsa, OK) & 75 \\
\hline Non-profit organization & 0.3 & 0.2 & 0.3 & 0.5 & 0.5 & 93 & 0.2 (Charlotte, NC) & 2.9 (Denver, CO) & 75 \\
\hline Television station & 0.1 & 0.1 & 0.3 & 0.4 & 0.6 & 145 & 0.2 (Omaha NE) & 5.7 (Columbus, $\mathrm{OH}$ ) & 75 \\
\hline State & 0.0 & 0.1 & 0.1 & 0.2 & 0.7 & 124 & 0.003 (Tulsa, OK) & 2.5 (Tucson, AZ) & 30 \\
\hline Community & 0.0 & 0.0 & 0.1 & 0.1 & 0.8 & 156 & 0.004 (Seattle, WA) & 3.5 (Tucson, AZ) & 20 \\
\hline Total & $1 \cdot 2$ & 0.9 & 1.4 & $2 \cdot 6$ & 1.3 & 51 & 1.3 (Omaha, NE) & $9 \cdot 3$ (Columbus, $\mathrm{OH}$ ) & 75 \\
\hline
\end{tabular}

${ }^{*}$ Calculated for DMA with exposure.

Table 3 Gross rating points (GRP) and content for federal televised obesity-prevention campaigns, USA, 2010-2011

\begin{tabular}{|c|c|c|c|c|c|c|c|}
\hline \multirow[b]{2}{*}{ Campaign name } & \multirow[b]{2}{*}{ Department(s) } & \multirow[b]{2}{*}{ Partners } & \multirow[b]{2}{*}{ Target audience } & \multirow[b]{2}{*}{ Main message(s) } & \multirow[b]{2}{*}{ Exposed markets } & \multicolumn{2}{|c|}{ Average annual GRP* } \\
\hline & & & & & & 2010 & 2011 \\
\hline Small Step & DHHS & Ad Council & General, youth & Healthy eating, physical activity & 75 & $412 \cdot 8$ & $347 \cdot 3$ \\
\hline Let's Move & DHHS, USDA & Ad Council & Youth & Healthy eating, physical activity & 75 & $237 \cdot 3$ & $1526 \cdot 2$ \\
\hline MyPyramid & USDA & Ad Council & Youth & Healthy eating, physical activity & 75 & $153 \cdot 8$ & $55 \cdot 9$ \\
\hline Wic & USDA & & Parents & Healthy eating & 18 & 314.5 & 233.6 \\
\hline Spot the Block & DHHS & & Youth & Healthy eating & 75 & $33 \cdot 0$ & 69.7 \\
\hline Play 60 & USDA & National Dairy Council, NFL, Ad Council & Youth & Physical activity & 75 & $25 \cdot 5$ & 61.4 \\
\hline 5 a day & USDA & & General & Healthy eating, physical activity & 75 & $23 \cdot 0$ & 0.1 \\
\hline Be a Player & DHHS & Ad Council & Youth & Physical activity & 26 & $16 \cdot 2$ & $14 \cdot 3$ \\
\hline Action Hero Alliance & DHHS & & Youth & Physical activity & 75 & 1.2 & 57.6 \\
\hline The Heart Truth & DHHS & Cheerios & General & Healthy eating, physical activity & 3 & 8.4 & $5 \cdot 0$ \\
\hline Healthier US Veterans & VA & & Veterans & Healthy eating, physical activity & 9 & $1 \cdot 1$ & 1.7 \\
\hline We Can! & DHHS & & Parents & Physical activity & 37 & 0.0 & 40.5 \\
\hline
\end{tabular}

WIC, Special Supplemental Nutrition Program for Women, Infants, and Children; DHHS, US Department of Health and Human Services; USDA, US Department of Agriculture; VA, US Department of Veterans Affairs; NFL, National Football League; DMA, designated market area.

${ }^{*}$ Calculated for DMA with exposure; advertisements per month can be derived by dividing GRP by 100 . 
Table 4 State and community televised obesity-prevention campaign characteristics, USA, 2010-2011

\begin{tabular}{|c|c|c|}
\hline & $n$ & $\%$ \\
\hline \multicolumn{3}{|l|}{ Sponsor } \\
\hline State & 14 & 41 \\
\hline Community ${ }^{*}$ & 20 & 59 \\
\hline CPPW-funded & 12 & 35 \\
\hline Private partners named & 4 & 12 \\
\hline \multicolumn{3}{|l|}{ Resources provided } \\
\hline Website & 30 & 88 \\
\hline Call line & 12 & 35 \\
\hline Seek health care/advice & 4 & 12 \\
\hline Social media & 1 & 3 \\
\hline \multicolumn{3}{|l|}{ Target audience } \\
\hline General & 16 & 47 \\
\hline Parents/expectant parents & 15 & 44 \\
\hline Youth & 3 & 9 \\
\hline \multicolumn{3}{|l|}{ Main message(s) } \\
\hline Healthy eating & 11 & 32 \\
\hline Physical activity & 4 & 12 \\
\hline Both & 18 & 53 \\
\hline Neither & 1 & 3 \\
\hline Nutritional recommendations & 19 & 56 \\
\hline Additional public health messages & 10 & 29 \\
\hline SSB focus & 3 & 9 \\
\hline \multicolumn{3}{|l|}{ Emotional and graphic content } \\
\hline Positive or neutral emotional valence & 32 & 94 \\
\hline Negative emotional valence & 2 & 6 \\
\hline Humour & 5 & 15 \\
\hline Graphic imagery & 1 & 3 \\
\hline \multicolumn{3}{|l|}{ Health consequences } \\
\hline Long-term health consequences & 12 & 32 \\
\hline Includes disease statistics & 5 & 15 \\
\hline Obesity/overweight mention & 16 & 47 \\
\hline Weight loss mention & 3 & 9 \\
\hline \multicolumn{3}{|l|}{ Adoption type } \\
\hline Commencement/increase & 21 & 62 \\
\hline Cessation/reduction & 4 & 12 \\
\hline Both & 8 & 24 \\
\hline Neither & 1 & 3 \\
\hline \multicolumn{3}{|l|}{ Factors in obesity } \\
\hline Image or mention of fast/junk food & 7 & 21 \\
\hline Image or mention of SSB & 6 & 18 \\
\hline Mention of screen time & 5 & 15 \\
\hline
\end{tabular}

CPPW, Communities Putting Prevention to Work; SSB, sugar-sweetened beverages.

*Includes Cherokee Nation, Oklahoma.

majority of these campaigns directed viewers to additional resources, typically websites. Twenty-nine per cent of campaigns included additional public health messages such as alcohol awareness, breast-feeding benefits or anti-smoking.

The long-term consequences of an unhealthy lifestyle were mentioned in twelve campaigns (32\%); these included diabetes (29\%) and heart disease (15\%). Five campaigns (15\%) included statistics about obesity-related diseases. Obesity or overweight was mentioned in sixteen campaigns (47\%), but only three of these campaigns (9\%) directly encouraged weight loss.

Campaigns typically encouraged initiation of new behaviours $(62 \%)$ rather than cessation/reduction of unhealthy behaviours (12\%). Eight campaigns (24\%) did both. The emotional valence of campaigns was neutral or positive in thirty-two campaigns (94\%) and negative in two (6\%). Humour was used in five campaigns (15\%) and graphic imagery was present in only one (3\%).

\section{Discussion}

Despite its association with increased sedentary screen time and exposure to advertising for unhealthy foods ${ }^{(53)}$, ironically television may also play a role in obesity prevention by providing information that empowers viewers to make healthier choices. However, our previous research showed that between 1999 and 2003, average household exposure to televised obesity-prevention advertising was low, with state and community obesityprevention campaigns airing in a small minority of $\mathrm{DMA}^{(32)}$. While federal obesity-prevention campaign ratings in 2010 and 2011 were exceeded by the VERB campaign in 2002 and 2003, state and community ratings were consistently higher in the current study (a 100\% increase between 2003 and 2010). By 2010-2011, average household exposure to governmental obesity-prevention campaigns was 1.6 advertisements per month. Additional exposure came from non-profit campaigns ( 0.5 exposures per month) and television station-sponsored PSA (0.4 exposures per month). In total, the average household exposure to public health obesity-prevention messages was 2.6 advertisements per month in 2010-2011. Exposure increased by $31 \%$ across the two years from $2 \cdot 3$ advertisements per month in 2010 to 3.0 in 2011.

The present study suggests some recent shifts in the sponsorship of obesity-prevention messages. Increases in exposure from 2010 to 2011 were driven largely by the introduction of the federal Let's Move campaign. Between 2010 and 2011, there were declines in advertising sponsored by non-profit organizations and state health departments, but increases in advertising funded by community health departments. Declines in state advertising in part reflect the wane of the Champions for Change campaign in California and Arizona, which garnered high ratings in 2010. The declines in state and non-profit exposure in 2011 also may reflect substitution effects as the federal government and community departments play a larger role in obesityprevention efforts. Non-profit organizations may increasingly serve as partners for governmental campaigns rather than acting as primary sponsors of advertising ${ }^{(36)}$. Different sponsoring organizations were associated with different messaging strategies, with federal campaigns typically targeting youth and state/community campaigns targeting general audiences or parents; this targeting is consistent with our finding that youth were more exposed than adults to federal campaigns. Compared with state/community campaigns, federal campaigns advocated physical activity more $(83 \% v .65 \%)$ and advocated dietary change less (67\% v. $85 \%)$.

Beyond achieving sufficient levels of exposure among target populations, public health television campaigns rely upon effective communication strategies to transform attitudes and behaviours. Our content analysis of state and community campaigns reveals several features of these campaigns that may be associated with effectiveness. First, 
whereas most state campaigns from 1999 to 2003 featured either a physical activity or dietary change message ${ }^{(32)}$, we found that most campaigns in the current study referenced both obesity-prevention strategies (53\%). Most campaigns also included concrete messages about which foods to seek out or to avoid ( $56 \%$ ). These characteristics have been associated with effectiveness ${ }^{(24)}$. Campaigns were more likely to encourage commencement/increase of healthy behaviours than cessation/reduction of unhealthy behaviours, a characteristic associated with larger effect size among health campaigns ${ }^{(15)}$. A number of campaigns referenced unhealthy foods (21\%) or SSB (18\%), although implications of the food industry in rising obesity rates varied in explicitness. Among tobacco-prevention campaigns, those highlighting the role of industry have been associated with effectiveness ${ }^{(54)}$.

Other campaign elements may not be optimal. For example, while the vast majority of advertisements referenced websites, social media resources were provided by only one campaign. Health departments underutilize new media relative to food companies ${ }^{(55)}$, and may be losing out on an important avenue of communication.

The effectiveness of other campaign elements we examined is unclear. In particular, it remains unknown whether negative emotion and graphic imagery in obesityprevention advertisements are associated with greater persuasive potential than other approaches, although evidence from other areas of public health messaging suggests that such appeals may sometimes be particularly effective, especially when they motivate fear in the context of viewers' high levels of efficacy ${ }^{(56-58)}$. While a few recent obesity-prevention campaigns drew controversy for fear appeals $^{(37)}$, we found that the majority of state and community campaigns in the present study had positive or neutral emotional valence. Campaigns were in fact more likely to include humour (five campaigns), an approach that is substantially less studied in the context of public health messaging but well established in other areas of advertising ${ }^{(59)}$. The only campaigns identified with a negative emotional valence were the Change the Future, West Virginia campaign and the Pouring on the Pounds campaign from New York City Department of Health. The latter was the only campaign that included graphic imagery (fat poured from a soda bottle and images of heart attack and amputation). While some prior studies have focused on depiction of negative health effects as a pathway to achieving an emotional reaction or fear response ${ }^{(60)}$, we further found that a number of campaigns mentioned obesity-related diseases without achieving an overall negative valence and without use of graphic imagery. Even where they do not produce substantial negative emotional arousal, appeals related to the longterm effects of unhealthy behaviours may nevertheless be effective in some contexts ${ }^{(27)}$.

Controversy has also emerged over whether campaigns that advocate healthy lifestyles should do so with or without reference to body image and weight ${ }^{(46)}$. Recently, some obesity-prevention advertising generated controversy for its tone with regard to weight status. For example, the Stop Sugarcoating it, Georgia campaign by Children's Healthcare of Atlanta, which launched in 2010, drew controversy for its portrayal of obese children as victims of bullying and low self-esteem. While some maintain that the campaign's message is consistent with the serious consequences of childhood obesity, others argue that the advertisements reinforce fat stigma ${ }^{(37,44)}$. Campaigns that emphasize weight or size without specifying concrete behaviours such as food choices or physical activity may not only elevate stigma but could also mislead viewers regarding the relationship between weight and health ${ }^{(4,43,61)}$. Such campaigns may also be less motivating than those focused on concrete behaviour changes ${ }^{(46)}$. In the present study, we found that nearly half of the thirty-four content-coded state and community campaigns mentioned obesity or overweight; yet, most advocated behavioural change across the board regardless of weight status, with few advocating weight loss specifically. It is unknown whether non-profit or television stationsponsored PSA campaigns were more likely to emphasize body image.

We found that a number of campaigns reflected alliances between health organizations and private partners. Publicprivate partnerships reflect the desire of public entities to disseminate their messages more widely and of companies to gain credibility or to position products as healthful ${ }^{(62)}$. Although we did not examine them in the present study, some food companies have produced their own campaigns emphasizing the importance of health. Industry-sponsored healthy lifestyle initiatives and corporate social responsibility campaigns have potential to inspire positive changes, but may also obscure the health impacts of commercial products $^{(63,64)}$. This ambiguity extends to television stations, with one study showing that, despite Nickelodeon's role in sponsoring healthy lifestyle campaigns such as Let's Just Play, eight of ten foods, beverages and restaurant meals advertised through its television station, magazine or characters were unhealthy ${ }^{(65)}$. Likewise, the character Shrek is featured in the DHHS Be a Player campaign, but has also been noted as a spokesperson for companies such as McDonald's, M\&Ms and Kellogg's, all of which market unhealthy foods to children ${ }^{(53)}$. It is unknown how dual associations of characters and brands may dilute healthpromoting messages.

Considerations of television's role in obesity have typically focused on the unhealthy effects of increasing screen time and the pervasiveness of obesogenic advertisements. In the USA, youth are exposed to frequent television commercials for foods and beverages, which have been associated with consumption behaviours and body-weight outcomes ${ }^{(66-69)}$. The Federal Trade Commission recently reported that forty-eight food and beverage companies spent \$US 1.8 billion on youth-targeted marketing in 
$2009^{(28)}$. Despite industry self-regulation through the Children's Food and Beverage Advertising Initiative, nutritional content analyses show that the vast majority of food and beverage advertising seen by children is for unhealthy products ${ }^{(70,71)}$. In a recent study of children's programming, over $95 \%$ of such advertisements were for products high in saturated fat, trans-fat, sugar or sodium ${ }^{(30)}$. The Rudd Center reported that, in 2010 and 2011, individuals aged 2-11, 12-17 and 18-49 years were exposed to thirteen, sixteen and twenty advertisements for food and beverages per day, respectively ${ }^{(72)}$. By comparing these exposure levels with the obesity-prevention exposure levels from the present study, we estimate that food and beverage advertisements were viewed over 300 times as often as obesity-prevention advertisements among children aged 2-11 years, over 500 times as often for teenagers aged 12-17 years and over 400 times as often among adults.

Despite increasing exposure between 2010 and 2011, it remains unclear whether public health obesity-prevention campaigns have achieved levels of exposure sufficient to produce significant effects in target populations. In a review article examining effects of anti-tobacco television advertising, researchers argued that campaigns require an average of 4800 GRP per year (forty-eight exposures) in order to achieve significant reductions in adult smoking prevalence ${ }^{(73)}$. In the current study, we note that the only state/community campaigns to achieve a comparable threshold were the Champions for Change campaign in Los Angeles in 2010 and the CPPW-funded Healthy Pima campaign in Tucson in 2011. No federal obesity-prevention campaign achieved this threshold in any of the top seventyfive media markets. Taking all obesity-prevention advertising together, fourteen markets achieved the 4800 GRP threshold in one or more study years, but on average - across all media markets - exposure levels were much lower (thirty-six annual exposures in 2011). Without further research on the relationship between campaign exposure and population obesity rates, it is difficult to evaluate whether obesityprevention campaigns are achieving appropriate exposure levels. It is important to note that obesity-prevention efforts differ substantially from anti-smoking efforts in that exposure may inspire more incremental changes related to a number of behaviours encompassing both physical activity and dietary choices; these changes may have important impacts on individuals' health.

The present study has several limitations and raises questions for future research. First, it is a descriptive study of campaign exposure and content, and we do not know whether or how campaigns impacted viewers' attitudes and behaviours; nor do we capture interventions in the community that may have been made in concert with media campaigns. Second, the present research focused on aggregate exposure and did not examine relative exposure by race or ethnicity. Such examinations would be useful given variation in rates of obesity and targeted food advertising ${ }^{(74)}$, as well as possible variation in response to advertising. Third, our two-year study period does not allow us to look longitudinally at changes in advertising content over time. Furthermore, while we capture some CPPW-funded efforts, additional campaigns have subsequently launched through CPPW as well as the DHHS Community Transformation Grant Program, which allocated \$US 103 million to sixty-one state and local government agencies, tribes and territories, and non-profit organizations in thirty-six states in $2011^{(75)}$. Fourth, our data set excludes advertisements that were aired only via spot cable, including the Philadelphia Department of Public Health's campaign focused on SSB consumption ${ }^{(22)}$. For this reason, we may have underestimated the true extent of obesity-prevention advertising; however, spot cable likely represents a small minority of such advertising, and we were able to locate all other campaigns from the study period that we identified through our literature review. Fifth, we did not content-code non-profit or television station-sponsored campaigns, which accounted for a nontrivial fraction of obesity-prevention advertising. It is unknown to what extent these campaigns incorporate evidence-based health communication strategies. Finally, although television remains the most dominant advertising medium, it nevertheless provides a limited window by which to estimate the amount of food and obesityprevention advertising to which households are exposed, with new media playing a growing role especially for youth $^{(28,76)}$. Fast-food marketers increasingly leverage websites such as Facebook and Twitter to network with customers and offer promotions, and some have also developed advergames and smart phone applications ${ }^{(77,78)}$. While some state and community health departments have adopted social media platforms ${ }^{(79,80)}$, they underutilize them relative to food companies ${ }^{(55)}$.

Exposure to televised obesity-prevention advertising appears to be increasing through efforts such as the federal Let's Move campaign and the CPPW grant programme. Nevertheless, exposure is extremely low relative to food advertising and varies widely by DMA. Despite recent controversy surrounding graphic or potentially stigmatizing obesity-prevention campaigns, we found that most state and community campaigns had neutral or positive emotional valence, advocated concrete behaviour change and did not advocate weight loss specifically. Further assessments of obesity-prevention and obesogenic media messages should examine the behavioural impact of these advertisements in target populations at high risk for obesity and must also account for the increasing role of new media.

\section{Acknowledgements}

Acknowledgement: The authors would like to thank Lisa Vera for her helpful suggestions on the manuscript. Financial support: This paper was supported by funding from the National Cancer Institute (NCI; award number 
R01CA138456). The NCI had no role in the design, analysis or writing of this article. Conflict of interest: None. Authorship: S.L.E. supervised the study; R.K., G.S., L.M.P. and S.L.E. conceived and designed the study; R.K., G.S. and S.L.E. analysed the data; R.K. wrote the paper; R.K., G.S., L.M.P. and S.L.E. provided feedback and suggestions on the manuscript. Ethics of human subject participation: Ethical approval was not required.

\section{References}

1. Ogden CL, Carroll MD, Kit BK et al. (2012) Prevalence of obesity and trends in body mass index among US children and adolescents, 1999-2010. JAMA 307, 483-490.

2. Flegal KM, Carroll MD, Kit BK et al. (2012) Prevalence of obesity and trends in the distribution of body mass index among US adults, 1999-2010. JAMA 307, 491-497.

3. Wang YC, McPherson K, Marsh T et al. (2011) Health and economic burden of the projected obesity trends in the USA and the UK. Lancet 378, 815-825.

4. Puhl RM \& Heuer CA (2009) The stigma of obesity: a review and update. Obesity (Silver Spring) 17, 941-964.

5. Cawley J \& Meyerhoefer C (2012) The medical care costs of obesity: an instrumental variables approach. $J$ Health Econ 31, 219-230

6. Chaput J-P, Klingenberg L, Astrup A et al. (2011) Modern sedentary activities promote overconsumption of food in our current obesogenic environment. Obes Rev 12, e12-e20.

7. Glade MJ (1999) Food, nutrition, and the prevention of cancer: a global perspective. American Institute for Cancer Research/World Cancer Research Fund, American Institute for Cancer Research, 1997. Nutrition 15, 523-526.

8. Cheadle A, Samuels SE, Rauzon S et al. (2010) Approaches to measuring the extent and impact of environmental change in three California community-level obesity prevention initiatives. Am J Public Health 100, 2129-2136.

9. Mehta S, Dimsdale J, Nagle B et al. (2013) Worksite interventions: improving lifestyle habits among Latin American adults. Am J Prev Med 44, 538-542.

10. Thande NK, Hurstak EE, Sciacca RE et al. (2009) Management of obesity: a challenge for medical training and practice. Obesity (Silver Spring) 17, 107-113.

11. Lankford T, Hardman D, Dankmeyer C et al. (2013) Analysis of state obesity legislation from 2001 to 2010. J Public Health Manag Pract 19, 3 Suppl. 1, S114-S118.

12. Lin B-H, Smith TA, Lee J-Y et al. (2011) Measuring weight outcomes for obesity intervention strategies: the case of a sugar-sweetened beverage tax. Econ Hum Biol 9, 329-341.

13. Frieden TR, Dietz W \& Collins J (2010) Reducing childhood obesity through policy change: acting now to prevent obesity. Health Aff (Millwood) 29, 357-363.

14. Noar SM (2006) A 10-year retrospective of research in health mass media campaigns: where do we go from here? J Health Commun 11, 21-42.

15. Snyder LB, Hamilton MA, Mitchell EW et al. (2004) A metaanalysis of the effect of mediated health communication campaigns on behavior change in the United States.J Health Commun 9, Suppl. 1, 71-96.

16. Randolph W \& Viswanath K (2004) Lessons learned from public health mass media campaigns: marketing health in a crowded media world. Annu Rev Public Health 25, 419-437.

17. Brown DR, Soares J, Epping JM et al. (2012) Stand-alone mass media campaigns to increase physical activity: a Community Guide updated review. Am J Prev Med 43, 551-561.

18. Wakefield MA, Loken B \& Hornik RC (2010) Use of mass media campaigns to change health behaviour. Lancet 376, 1261-1271.
19. Berkowitz JM, Huhman M \& Nolin MJ (2008) Did augmenting the VERB campaign advertising in select communities have an effect on awareness, attitudes, and physical activity? Am J Prev Med 34, 6 Suppl., S257-S266.

20. Beaudoin CE, Fernandez C, Wall JL et al. (2007) Promoting healthy eating and physical activity short-term effects of a mass media campaign. Am J Prev Med 32, 217-223.

21. Berry TR, Spence JC, Plotnikoff RC et al. (2009) A mixed methods evaluation of televised health promotion advertisements targeted at older adults. Eval Program Plann 32, 278-288.

22. Jordan A, Piotrowski JT, Bleakley A et al. (2012) Developing media interventions to reduce household sugar-sweetened beverage consumption. Ann Am Acad Polit Soc Sci 640, $118-135$.

23. Hornik R \& Kelly B (2007) Communication and diet: an overview of experience and principles. J Nutr Educ Behav 39, 2 Suppl., S5-S12.

24. Greaves CJ, Sheppard KE, Abraham C et al. (2011) Systematic review of reviews of intervention components associated with increased effectiveness in dietary and physical activity interventions. BMC Public Health 11, 119.

25. Lupton D (2014) The pedagogy of disgust: the ethical, moral and political implications of using disgust in public health campaigns. Crit Public Health doi: 10.1080/ 09581596.2014 .885115$.

26. Biener L \& Taylor TM (2002) The continuing importance of emotion in tobacco control media campaigns: a response to Hastings and MacFadyen. Tob Control 11, 75-77.

27. Durkin SJ, Biener L \& Wakefield MA (2009) Effects of different types of antismoking ads on reducing disparities in smoking cessation among socioeconomic subgroups. Am J Public Health 99, 2217-2223.

28. Federal Trade Commission (2012) A Review of Food Marketing to Children and Adolescents: Follow-Up Report. Washington, DC: FTC; available at http://www.ftc.gov/os/ 2012/12/121221foodmarketingreport.pdf

29. Powell LM, Schermbeck RM, Szczypka G et al. (2011) Trends in the nutritional content of television food advertisements seen by children in the United States: analyses by age, food categories, and companies. Arch Pediatr Adolesc Med 165, 1078-1086.

30. Powell LM, Schermbeck RM \& Chaloupka FJ (2013) Nutritional content of food and beverage products in television advertisements seen on children's programming. Child Obes 9, 524-531.

31. Powell LM, Harris JL \& Fox T (2013) Food marketing expenditures aimed at youth: putting the numbers in context. Am J Prev Med 45, 453-461.

32. Emery SL, Szczypka G, Powell LM et al. (2007) Public health obesity-related TV advertising: lessons learned from tobacco. Am J Prev Med 33, 4 Suppl., S257-S263.

33. Banghart PL (2012) Comprehensive Obesity Prevention in Early Childhood: Promising Federal and State Initiatives. New York: Columbia University; available at http:// academiccommons.columbia.edu/catalog/ac: 146793

34. Bunnell R, O'Neil D, Soler R et al. (2012) Fifty communities putting prevention to work: accelerating chronic disease prevention through policy, systems and environmental change. J Community Health 37, 1081-1090.

35. Stolberg SG (2010) Childhood Obesity Battle Is Taken Up by First Lady. The New York Times, 9 February. http://www. nytimes.com/2010/02/10/health/nutrition/10obesity.html (accessed May 2013).

36. Hersey J, Kelly B, Roussel A et al. (2012) The value of partnerships in state obesity prevention and control programs. Health Promot Pract 13, 222-229.

37. Katz DL, Murimi M, Pretlow RA et al. (2012) Exploring effectiveness of messaging in childhood obesity campaigns. Child Obes 8, 97-105. 
38. Klein JD \& Dietz W (2010) Childhood obesity: the new tobacco. Health Aff (Millwood) 29, 388-392.

39. Graham J (2012) Obesity fight needs ambitious campaign, health leaders say. USA Today, 4 May. http://www.usatoday. com/news/health/story/2012-05-05/childhood-obesity-tobacco/ 54745872/1 (accessed December 2012).

40. Brownell KD \& Warner KE (2009) The perils of ignoring history: Big Tobacco played dirty and millions died. How similar is Big Food? Milbank Q 87, 259-294.

41. Chopra M (2004) Tobacco and obesity epidemics: not so different after all? BMJ 328, 1558-1560.

42. Chaloupka FJ, Powell LM \& Chriqui JF (2011) Sugarsweetened beverages and obesity: the potential impact of public policies. J Policy Anal Manag 30, 645-655.

43. Walls HL, Peeters A, Proietto J et al. (2011) Public health campaigns and obesity - a critique. BMC Public Health 11, 136.

44. Kliff S (2012) Georgia's shocking anti-obesity ad campaign. The Washington Post Blogs, 3 January. http://www. washingtonpost.com/blogs/wonkblog/post/georgias-shockinganti-obesity-ad-campaign/2012/01/03/gIQAZB8HYP_blog.html (accessed December 2012).

45. Puhl R, Luedicke J \& Peterson JL (2013) Public reactions to obesity-related health campaigns: a randomized controlled trial. Am J Prev Med 45, 36-48.

46. Puhl R, Peterson JL \& Luedicke J (2013) Fighting obesity or obese persons? Public perceptions of obesity-related health messages. Int J Obes (Lond) 37, 774-782.

47. Dooley JA, Deshpande S \& Adair CE (2010) Comparing adolescent-focused obesity prevention and reduction messages. J Bus Res 63, 154-160.

48. Television Bureau of Advertising (2012) Nielsen 2012-2013 DMA Ranks. http://www.tvb.org/measurement/131627 (accessed April 2013)

49. Mongeau PA (1998) Another look at fear-arousing persuasive appeals. In Persuasion: Advances Through Meta-analysis, pp. 53-68 [M Allen and RW Preiss, editors]. Cresskill, NJ: Hampton.

50. Vega T (2013) Using Humor to Talk About Birth Control. The New York Times, 10 November. http://www.nytimes. com/2013/11/11/business/media/using-humor-to-talk-aboutbirth-control.html (accessed November 2013)..

51. Wilson BJ (2007) Designing media messages about health and nutrition: what strategies are most effective? J Nutr Educ Behav 39, 2 Suppl., S13-S19.

52. Feinstein AR \& Ciccheti DV (1990) High agreement but low kappa: I. The problems of two paradoxes. J Clin Epidemiol 43, 543-549.

53. Jordan $\mathrm{AB}$ (2008) Overweight and Obesity in America's Children: Causes, Consequences, Solutions. Thousand Oaks, CA: SAGE Publications.

54. Malone RE, Grundy Q \& Bero LA (2012) Tobacco industry denormalisation as a tobacco control intervention: a review. Tob Control 21, 162-170.

55. Royne MB \& Levy M (2011) Marketing for public health: we need an app for that. J Consum Aff $\mathbf{4 5}, 1-6$.

56. Witte K \& Allen M (2000) A meta-analysis of fear appeals: implications for effective public health campaigns. Health Educ Behav 27, 591-615.

57. Emery S, Szczypka G, Abril PE et al. (2014) Are you scared yet? Evaluating fear appeal messages in tweets about the Tips Campaign. J Commun 64, 278-295.

58. Peters G-JY, Ruiter RAC \& Kok G (2013) Threatening communication: a critical re-analysis and a revised metaanalytic test of fear appeal theory. Health Psychol Rev 7, Suppl. 1, S8-S31.

59. Eisend M (2009) A meta-analysis of humor in advertising. $J$ Acad Mark Sci 37, 191-203.

60. Biener L, Ji M, Gilpin EA et al. (2004) The impact of emotional tone, message, and broadcast parameters in youth anti-smoking advertisements. J Health Commun 9, 259-274.
61. Oliver JE (2005) Fat Politics: The Real Story Behind America's Obesity Epidemic. New York: Oxford University Press.

62. Koplan JP \& Brownell KD (2010) Response of the food and beverage industry to the obesity threat. JAMA 304, 1487-1488.

63. Dorfman L, Cheyne A, Friedman LC et al. (2012) Soda and tobacco industry corporate social responsibility campaigns: how do they compare? PLoS Med 9, e1001241.

64. Kraak VI, Kumanyika SK \& Story M (2009) The commercial marketing of healthy lifestyles to address the global child and adolescent obesity pandemic: prospects, pitfalls and priorities. Public Health Nutr 12, 2027-2036.

65. Batada A \& Wootan MG (2007) Nickelodeon markets nutrition-poor foods to children. Am J Prev Med 33, 48-50.

66. Lobstein T \& Dibb S (2005) Evidence of a possible link between obesogenic food advertising and child overweight. Obes Rev 6, 203-208.

67. Institute of Medicine (2005) Food Marketing to Children and Youth: Threat or Opportunity?. Washington, DC: National Academies Press; available athttp://www.iom.edu/ Reports/2005/Food-Marketing-to-Children-and-Youth-Threator-Opportunity.aspx

68. Chou S-Y, Rashad I \& Grossman M (2008) Fast-food restaurant advertising on television and its influence on childhood obesity. J Law Econ 51, 599-618.

69. Andreyeva T, Kelly IR \& Harris JL (2011) Exposure to food advertising on television: associations with children's fast food and soft drink consumption and obesity. Econ Hum Biol 9, 221-233.

70. Kraak VI, Story M, Wartella EA et al. (2011) Industry progress to market a healthful diet to American children and adolescents. Am J Prev Med 41, 322-333.

71. Cheyne A, Gonzalez P, Mejia P et al. (2013) Food and Beverage Marketing to Children and Adolescents: Limited Progress by 2012, Recommendations for the Future. Princeton, NJ: Robert Wood Johnson Foundation; available at http:// www.rwjf.org/en/research-publications/find-rwjf-research/ 2013/02/food-and-beverage-marketing-to-children-andadolescents.html

72. Yale Rudd Center for Food Policy and Obesity (2012) Trends in Television Food Advertising to Young People: 2011 Update. New Haven, CT: Yale University, Rudd Center for Food Policy and Obesity; available at http://www. yaleruddcenter.org/resources/upload/docs/what/reports/ RuddReport_TVFoodAdvertising_5.12.pdf

73. Durkin S, Brennan E \& Wakefield M (2012) Mass media campaigns to promote smoking cessation among adults: an integrative review. Tob Control 21, 127-138.

74. Grier SA \& Kumanyika SK (2008) The context for choice: health implications of targeted food and beverage marketing to African Americans. Am J Public Health 98, 1616-1629.

75. Centers for Disease Control and Prevention (2013) Community Transformation Grants (CTG) States and Communities Program Descriptions. http://www.cdc.gov/communitytransformation/ funds/programs.htm (accessed May 2013).

76. Montgomery KC \& Chester J (2009) Interactive food and beverage marketing: targeting adolescents in the digital age. $J$ Adolesc Health 45, 3 Suppl., S18-S29.

77. Harris JL, Schwartz MB, Brownell KD et al. (2010) Fast Food FACTS: Evaluating Fast Food Nutrition and Marketing to Youth. New Haven, CT: Yale University; Rudd Center for Food Policy and Obesity; available at: http://www.rwjf.org/ content/dam/farm/reports/reports/2010/rwjf68794

78. Montgomery KC, Chester J, Grier SA et al. (2012) The new threat of digital marketing. Pediatr Clin North Am 59, 659-675.

79. Thackeray R, Neiger BL, Smith AK et al. (2012) Adoption and use of social media among public health departments. BMC Public Health 12, 242.

80. Harris JK, Mueller NL \& Snider D (2013) Social media adoption in local health departments nationwide. $\mathrm{Am} \mathrm{J}$ Public Health 103, 1700-1707. 
Appendix

State and community televised obesity-prevention campaigns, USA, 2010-2011

\begin{tabular}{|c|c|c|c|c|c|}
\hline Campaign & State & Community & CPPW & 2010 GRP & 2011 GRP \\
\hline Champions for Health & $\mathrm{AL}$ & Jefferson County & yes & 662 & 715 \\
\hline Champions for Change & $A Z$ & & & 5047 & 4198 \\
\hline Healthy Pima & $A Z$ & Pima County & yes & 0 & 8515 \\
\hline Champions for Change & $\mathrm{CA}$ & & & 15039 & 211 \\
\hline Healthy Works & $\mathrm{CA}$ & San Diego & yes & 0 & 748 \\
\hline Flat 14ers & $\mathrm{CO}$ & Tri-county & yes & 153 & 313 \\
\hline Cuidandose de la Diabetes* & $\mathrm{CO}$ & Weld County & & 1 & 19 \\
\hline Moderate exercise message & FL & Escambia County & & 73 & 0 \\
\hline Make Healthy Happen Miami & FL & Miami-Dade & yes & 0 & 2032 \\
\hline Fit City & IN & Marion County & & 14 & 0 \\
\hline Eat Smart Play Hard & KS & & & 0 & 229 \\
\hline Healthy Hometown & KY & Louisville & yes & 0 & 1133 \\
\hline Healthy ageing message & MA & & & 271 & 270 \\
\hline SugarSmarts & MA & Boston & yes & 0 & 1266 \\
\hline Breastmilk: Every Ounce Counts & $\mathrm{Ml}$ & & & 3872 & 1401 \\
\hline Get Growing with WIC & MI & & & 0 & 95 \\
\hline Eat Smart, Move More & NC & & & 218 & 1 \\
\hline Smart Start & NC & & & 13 & 0 \\
\hline Healthy Moms Have Healthy Babies & NC & Guilford County & & 0 & 13 \\
\hline 10 pounds in 10 weeks & NV & Clark County (Southern Nevada Health District) & yes & 218 & 0 \\
\hline WIC breast-feeding message & NY & & & 898 & 0 \\
\hline Pouring on the Pounds & NY & New York City & & 87 & 937 \\
\hline Healthy Ohio & $\mathrm{OH}$ & & & 1742 & 199 \\
\hline GetUp & $\mathrm{OH}$ & Dayton \& Montgomery County & & 430 & 0 \\
\hline Tulsa Play & OK & Tulsa & & 1008 & 1703 \\
\hline Diabetes Prevention Program & OK & Cherokee Nation & yes & 0 & 692 \\
\hline Diabetes Prevention and Management & OR & Baker County & & 0 & 18 \\
\hline Cut Back the Sugar & RI & & & 0 & 1467 \\
\hline Eat Smart, Move More & SC & & & 920 & 0 \\
\hline Breastmilk: Every Ounce Counts & TX & & & 2952 & 0 \\
\hline SABalance & $\mathrm{TX}$ & San Antonio & yes & 0 & 2492 \\
\hline Power Your Life & UT & & & 363 & 0 \\
\hline Step Up Spokane & WA & Spokane & & 95 & 127 \\
\hline Let's Do This! King County & WA & King County & yes & 0 & 9 \\
\hline Change the Future WV & WV & Mid-Ohio Valley & yes & 412 & 1009 \\
\hline All state and community & & & & 34488 & 29811 \\
\hline
\end{tabular}

CPPW, Communities Putting Prevention to Work; GRP, gross rating points; WIC, Special Supplemental Nutrition Program for Women, Infants, and Children. *Spanish-only campaign, not coded for content. 